\title{
Cone Beam Computed Tomography: A New Trend for Craniofacial Treatment Planning
}

\author{
Preetinder Singh
}

Respected Editor,

$\mathrm{W}$ ith reference to an excellent article published in your esteemed journal recently regarding the use of cone beam computed tomography (CBCT) for the detection of external root resorption, ${ }^{[1]}$ I would like to add some vital information on the use of CBCT in craniofacial field in the present era. CBCT allows the creation in "real time" of images not only in the axial plane but also 2-dimensional images in the coronal, sagittal, and even oblique or curved image planes - a process known as multiplanar reformation (MPR). Also, CBCT data are amenable to reformation in a volume, rather than a slice, providing 3-dimensional (3D) picture and information. The value of CBCT imaging in dental implant planning, surgical assessment of various oral pathologies, assessment of temporomandibular joint, and pre- and postoperative assessment of craniofacial fractures and trauma has been reported. ${ }^{[2,3]} \mathrm{CBCT}$ imaging is now being directed toward 3D cephalometry and detection of orthognathic deformities. Being considerably smaller, CBCT equipment has a greatly reduced physical footprint and is approximately 20-25\% of the cost of conventional CT. CBCT provides images of high contrasting structures and is therefore particularly well-suited toward the imaging of osseous structures of the craniofacial area, providing an easy and accurate treatment planning. CBCT advantages include rapid scan time, image accuracy, beam limitation, and reduced patient radiation dose compared to conventional CT. CBCT is capable of providing accurate, sub-millimeter resolution images in formats enabling 3D visualization of the complexity of the maxillofacial region. CBCT examination has been found useful in preoperative diagnostics prior to the surgical removal of lower impacted third molars. In a recent study, CBCT was found to be superior to panoramic images in predicting neurovascular bundle exposure during the extraction of impacted lower third molars. ${ }^{[4]}$ Though CBCT is of tremendous use as mentioned above, further technical improvements to CBCT devices can be anticipated in the future.

\section{REFERENCES}

1. Shokri A, Mortazavi H, Salemi F, Javadian A, Bakhtiari H, Matlabi H. Diagnosis of simulated external root resorption using conventional intraoral film radiography, CCD, PSP, and CBCT: A comparison study. Biomed J 2013;36:18-22.

2. Sukovic P. Cone beam computed tomography in craniofacial imaging. Orthod Craniofac Res 2003;6(Suppl 1):31-6.

3. Ziegler CM, Woertche R, Brief J, Hassfeld S. Clinical indications for digital volume tomography in oral and maxillofacial surgery. Dentomaxillofac Radiol 2002;31:126-30.

4. Tantanapornkul W, Okouchi K, Fujiwara Y, Yamashiro M, Maruoka Y, Ohbayashi N, et al. A comparative study of cone-beam computed tomography and conventional panoramic radiography in assessing the topographic relationship between the mandibular canal and impacted third molars. Oral Surg Oral Med Oral Pathol Oral Radiol Endod 2007;103:253-9.

From the Department of Periodontology and Oral Implantology, SDD Hospital and Dental College, Barwala, Haryana, India Received: Apr. 3, 2013; Accepted: May 23, 2013

Correspondence to: Dr. Preetinder Singh, Department of Periodontology and Oral Implantology, SDD Hospital and Dental College, Barwala, Haryana, India. 28, Sangam Enclave, Sector 48-A, Chandigarh 160047, India. Tel: 91-991 56 52946; Fax: 91-1734-258195; E-mail: preetinder.perio@yahoo.com

DOI: $10.4103 / 2319-4170.113237$ 